\title{
How should molecular findings be integrated in the classification for lung cancer?
}

\author{
Yin P. Hung ${ }^{1}$, Lucian R. Chirieac ${ }^{2}$ \\ ${ }^{1}$ Department of Pathology, Massachusetts General Hospital and Harvard Medical School, Boston, MA, USA; ${ }^{2}$ Departments of Pathology, Brigham \\ and Women's Hospital and Harvard Medical School, Boston, MA, USA \\ Contributions: (I) Conception and design: None; (II) Administrative support: None; (III) Provision of study materials or patients: None; (IV) \\ Collection and assembly of data: None; (V) Data analysis and interpretation: None; (VI) Manuscript writing: All authors; (VII) Final approval of \\ manuscript: All authors. \\ Correspondence to: Yin P. Hung, MD, PhD. Department of Pathology, Massachusetts General Hospital, 55 Fruit Street, Boston, MA 02114, USA. \\ Email: yphung@mgh.harvard.edu.
}

\begin{abstract}
The use of molecular diagnostics in the diagnosis and management of patients with advanced lung cancer has become widespread. Although molecular classification has increasingly been incorporated in the pathologic classification of certain types of human tumors (particularly within the hematologic, glial, and bone/soft tissue malignancies), genetic findings have not been formally incorporated into the pathologic classification of lung cancer, which presently relies solely on the assessment of histologic and immunophenotypic characteristics. Whether molecular classification should be adopted in lung cancer would depend on the diagnostic, prognostic, and predictive impacts of such classification-and whether these impacts confer significant values additive to those derived from the routine histologic and immunophenotypic assessment. We provide a brief overview on the genetics of lung cancer, including adenocarcinoma, squamous cell carcinoma, and neuroendocrine tumors (small cell carcinoma, large cell neuroendocrine carcinoma, and carcinoid tumors). We consider the values of molecular information with some examples, in terms of the current diagnostic, prognostic, and predictive impacts. Finally, we discuss the conceptual and technical challenges of adopting a molecular classification for lung cancer in clinical management for patients. While there are conceptual and technical hurdles to tackle in implementing molecular classification in the pathologic classification of lung cancer, such integrated histologic-molecular diagnosis may allow one to personalize and optimize therapy for patients with advanced lung cancer.
\end{abstract}

Keywords: Molecular diagnostics; molecular classification; lung cancer; EGFR; ALK

Submitted Jan 15, 2019. Accepted for publication Jun 19, 2020.

doi: $10.21037 /$ tlcr-20-153

View this article at: http://dx.doi.org/10.21037/tlcr-20-153

\section{Introduction}

In the last few years, the use of molecular diagnostics has become widespread and integrated in the management of patients with advanced lung cancer. Nonetheless, genetic findings have not been formally incorporated into the pathologic classification of lung cancer, which presently relies solely on the assessment of its histologic and immunophenotypic features (1). Given the extensive published literature on both lung cancer and molecular diagnostics, each of which is a complex topic, we will not address these two topics in a comprehensive fashion. Instead, we focus on several salient aspects of lung cancer genetics in the framework of their impacts on lung cancer diagnosis and treatment.

Molecular classification has increasingly been incorporated in the pathologic classification of human tumors. In fact, the molecular status of certain genes is required for the pathologic diagnosis for some tumors (particularly within the hematologic, glial, and bone/soft tissue malignancies) in the World Health Organization 
Table 1 Brief overview of molecular alterations of lung tumors in this review

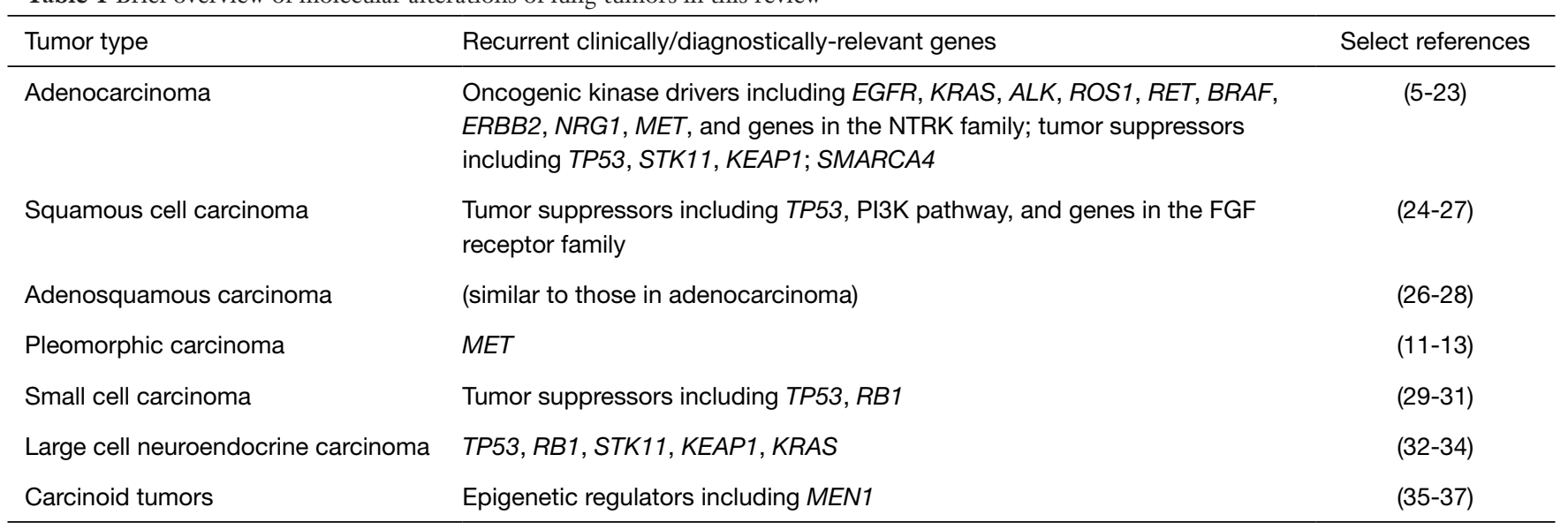

(WHO) classification of tumors (2-4). Nonetheless, whether molecular classification should be adopted in lung cancer would depend on the diagnostic, prognostic, and predictive impacts of such classification-and whether these impacts confer significant values additive to those derived from the routine histologic and immunophenotypic assessment. We will discuss these considerations, as well as the conceptual and technical challenges of implementing a molecular classification in the clinical management of lung cancer.

\section{Brief overview on our current understanding on the genetics of lung cancer}

Histologically, lung tumors are classified into several categories: the most commonly encountered categories include adenocarcinoma and squamous cell carcinoma, rarely other non-small cell lung carcinomas (adenosquamous carcinoma, sarcomatoid carcinoma, and others). Neuroendocrine tumors of the lung comprise a distinct group that includes small cell carcinoma, large cell neuroendocrine carcinoma, and carcinoid tumors. Here, we will primarily focus on some of the more common tumor types listed above, rather than other rare categories (salivary gland-type tumors, papillomas, adenomas, and mesenchymal and lymphohistiocytic tumors) (1). As expected, given the morphologic diversity, lung cancer shows tremendous genetic diversity with multiple distinct and overlapping molecular subgroups, some of which are associated with histologic categories and subtypes (Table 1).

Genetically, lung adenocarcinoma comprises a collection of diverse subgroups; approximately $60-70 \%$ of tumors are known to harbor oncogenic driver mutations (such as in $K R A S, E G F R, B R A F$, or ERBB2), rearrangements (such as in ALK, ROS1, RET, NRG1, or one of the NTRK genes), or structural alterations (such as in $M E T$ with exon 14 skipping) $(5,6)$. Some of these alterations appear to show histologic correlates. For instance EGFR-mutant lung adenocarcinomas often show an acinar or papillarypredominant pattern (so-called terminal respiratory unit phenotype) $(7,8)$. ALK-rearranged lung adenocarcinomas typically show a solid-to-cribriform pattern with signetring cell features $(9,10)$. Adenocarcinoma with $M E T$ exon 14 splice site mutation can be seen in up to $~ 30 \%$ of nonsmall cell lung carcinomas with pleomorphic histology (11-13). NRG1-rearranged lung adenocarcinomas often show invasive mucinous histology $(14,15)$. However, these molecular-histologic correlates are not absolute, with diverse and overlapping histologic patterns reported in adenocarcinomas with those alterations mentioned above, as well as those with oncogenic rearrangements in ROS1 $(16,17)$, RET $(18-20)$, or one of the NTRK genes (21). Identification of molecular subtypes in lung adenocarcinomas therefore relies primarily on molecular techniques, rather than histologic and immunophenotypic features alone $(22,23)$. In the United States, according to the 2018 clinical testing guideline from the College of American Pathologists (CAP), International Association for the Study of Lung Cancer (IASLC), and Association for Molecular Pathology (AMP), the recommended "musttest" molecular markers for patients with advanced lung adenocarcinoma include $E G F R, A L K$, and ROS1, with an expanded panel that includes KRAS, BRAF, MET, RET, and ERBB2 (22).

Lung squamous cell carcinoma is characterized by 
frequent mutations in the PI3K growth factor signaling pathway and in tumor suppressor genes such as TP53 $(24,25)$. Unlike adenocarcinoma, squamous cell carcinoma typically lacks oncogenic driver mutations (such as $K R A S$, $E G F R$, and $B R A F$ ) or rearrangements (such as $A L K$ and ROS1) as discussed above. Lung adenosquamous carcinoma, which contains both adenocarcinoma and squamous cell carcinoma with each comprising at least $10 \%$ of the tumor, has been shown to harbor mutations in EGFR, KRAS, and rarely $B R A F$ (26-28) or RET rearrangement (20). Genetically, lung adenosquamous carcinoma thus resembles lung adenocarcinoma rather than lung squamous cell carcinoma.

Among primary neuroendocrine tumors of the lung, small cell carcinoma harbors inactivating mutations in both TP53 and RB1 in $>90 \%$ of tumors (29-31), a subset showing $M Y C$ gene amplification (31). On the other hand, genetically, large cell neuroendocrine carcinoma is heterogeneous and comprises multiple subgroups that are small cell carcinoma-like, non-small cell carcinoma-like, and carcinoid-like $(32,33)$. Mutations in NTRK family members have also been described in large cell neuroendocrine carcinoma but not in carcinoid tumors or small cell carcinoma (34). While carcinoid tumors are considered with small cell carcinoma and large cell neuroendocrine carcinoma within the group of pulmonary neuroendocrine tumors, carcinoids lack mutations in tumor suppressors and are genetically distinct from small cell carcinoma and large cell neuroendocrine carcinoma; instead, carcinoid tumors are characterized by a relatively low tumor mutational burden, with a subset of tumors harboring mutations in MEN1 and epigenetic regulators such as ARID1A and PSIP1 (35-37).

\section{Diagnostic, prognostic, and predictive values of using molecular classification in lung cancer}

Molecular diagnostics can be helpful in some instances in which the histologic and immunophenotypic features may be incomplete or inconclusive for the diagnosis. For instance, for a patient (particularly with light or never smoking history) diagnosed with squamous cell carcinoma by a biopsy, identification of mutations such as EGFR characteristic of lung adenocarcinoma would imply that the tumor is likely an adenosquamous carcinoma, with the adenocarcinoma component not been sampled $(26,27)$. Another example involves a sarcomatoid tumor of the chest wall, in which distinction between pleomorphic/ spindle cell carcinoma and sarcomatoid mesothelioma can be difficult (38). Identification of MET exon 14 splice site mutation (characteristic of a subset of pleomorphic/ spindle cell carcinomas), if present, would strongly favor the diagnosis of pleomorphic/spindle cell carcinoma rather than mesothelioma. Furthermore, targeted nextgeneration sequencing can provide us the mutation status of dozens to hundreds of genes; with sufficient number of genes interrogated, mutational patterns can be derived $(39,40)$ and potentially provide clues for the primary site in challenging cases. For instance, an ultraviolet mutational signature may suggest a tumor with a cutaneous origin (such as melanoma, squamous cell carcinoma); while a smokingrelated mutational signature in a tumor from a smoker may suggest a primary lung malignancy (23) or other tumors that frequently harbor tobacco mutational signature such as head and neck squamous cell carcinoma (40).

Studies on the prognostic impacts of molecular subtype in lung cancer are ongoing, however with no definitive consensus currently. The association between EGFR mutation status and patient survival has both been reported and disputed in several studies including meta-analysis (41-43). Similarly, the published literature on the association between $A L K$ rearrangement status and patient survival are not entirely consistent, with association reported in some studies but disputed in others $(43,44)$. These inconsistencies may be due to the types of patient cohort and statistical methodology, since molecular characteristics (such as EGFR or $A L K$ mutation status) can vary with clinicopathologic factors such as ethnicity, age, gender, smoking history (10,45-48), and histologic types (7-9,49), some of which correlate with survival and confound the association between molecular subtype and patient outcome. The effect on outcome also appears to vary depending on the particular EGFR or ALK alterations; for instance, among patients with $E G F R$-mutant lung adenocarcinomas, the best outcome was noted in those with EGFR exon 19 deletion mutations (50-52). Collectively, in a recent clinicogenomic study involving $>28,000$ non-small cell lung cancer patients (including $>3,500$ patients with advanced disease) in the United States, alterations in a National Comprehensive Cancer Network (NCCN)-listed driver gene (which includes EGFR, ALK, ROS1, MET, BRAF, RET, and ERBB2) are associated with longer survival in advanced disease (53). In a retrospective study on $>2,100$ non-small cell lung carcinoma patients with newly diagnosed brain metastases, the addition of $E G F R$ and $A L K$ mutation status information to previously known prognostic factors (such as age, 
performance status, and number of cranial and extracranial metastases) improved the performance of the prognostic assessment (54), suggesting the values of incorporating molecular information in predicting outcome for this group of patients. Whether this can be generalized to patients in other settings or those with uncommon EGFR or $A L K$ mutations remains unclear, however.

Molecular diagnostics has become incorporated in the treatment planning for many advanced lung cancer patients. For patients with advanced non-small cell lung carcinomas that harbor oncogenic sensitizing EGFR mutations, EGFR-targeted tyrosine kinase inhibitors have been shown to be superior to standard chemotherapy in both first-line and non-first-line settings $(55,56)$. For patients with advanced non-small cell lung carcinomas that harbor $A L K$ rearrangements, ALK-targeted inhibitors have emerged as the standard of care (57-60). Similarly, ROS1targeted therapy has demonstrated efficacy in patients with advanced non-small cell lung carcinomas that harbor ROS1 rearrangements (59). Combined BRAF and MEK inhibition has been used to treat patients with advanced BRAF V600Emutant lung adenocarcinomas $(61,62)$. Recently, TRKtargeted therapy has been shown to be efficacious across a wide range of NTRK-rearranged tumors regardless of the tumor origins including lung (63); identification of this molecular subtype in lung cancer, albeit rare [ 0.2\%; (21)], imparts therapeutic significance.

\section{Conceptual challenges of using molecular classification in lung cancer}

In addition to demonstrating values additive to histomorphology, molecular classification should be practical in its implementation. Molecular categories should be well-defined, each with consistent results derived irrespective of laboratories or techniques involved. While in theory simple, in practice there are several conceptual and technical challenges.

Since a classification system relies on the delineation of categories, what conceptually constitutes a molecular category? First, should each category be defined at the level of DNA (mutations, rearrangements, copy number alterations), RNA (expression status), or even epigenetic regulation? For instance, small cell lung carcinoma appears homogeneous genetically with frequent $R B 1$ and TP53 mutations based on the mutation analysis (29-31) but transcriptionally comprises subgroups with distinct expression profiles, with one of the recent proposed nomenclature based on the expression of four factors: ASCL1, NeuroD1, POU2F3, and YAP1 (64). Currently, these four expression subtypes have no immediate prognostic or predictive impacts on the clinical management of small cell carcinoma. Although recent development to target ASCL1positive small cell carcinomas using an anti-DLL3 antibodydrug conjugate have been discontinued due to toxicity and limited efficacy, clinical trials on other targeted therapies in small cell carcinoma are ongoing (65). Should small cell carcinoma be classified using one or several molecular categories then?

Second, how granular should each molecular category be defined? For example, would EGFR-mutant or $A L K$ rearranged lung cancer suffice-or should the exact mutations involved be specified? If latter, how many categories should there be, given the theoretically nearly infinite combinations of mutations in human tumors? While most $A L K$-rearranged or $E G F R$-mutant lung tumors respond to their respective targeted therapy, some of the alterations are resistant mutations rather than sensitizing mutations. Among $A L K$-rearranged lung adenocarcinomas, $A L K$ fusion variants differ in outcome and resistance profile, with $E M L 4-A L K$ variant 3 associated with increased incidence of secondary $A L K$ resistance mutations including G1202R (66). Among EGFR-mutant lung adenocarcinomas, in addition to the activating and sensitizing mutations (most commonly EGFR L858R in exon 21 and in-frame deletion of the ELREA motif in exon 19), rare mutations that are resistant to most EGFR-targeted inhibitors (for instance $E G F R$ exon 20 in-frame insertion) have been noted (67). Compound EGFR mutations, characterized by the presence of multiple mutations (some of which are uncommon) within a tumor, are also present in a subset of patients $(68,69)$. Functional impacts of these mutations can be interrogated using high-throughput phenotyping (70); nonetheless, clinical significance of many uncommon EGFR variants remains poorly understood (71), posing substantial challenges on their classification.

Third, how should we handle the plasticity of the molecular category, especially given the increasing use of targeted therapy that provides selective pressure on the tumor? For instance, a subset of EGFR-mutant lung adenocarcinoma undergoes histologic transformation into small cell carcinoma as a mechanism of acquired resistance to EGFR-targeted therapy (72), with the risk of transformation increased by the presence of concurrent TP53 and RB1 mutations (72-74). Transdifferentiation of $E G F R$-mutant lung adenocarcinoma into squamous 
cell carcinoma has also been reported as a mechanism of acquired resistance to EGFR-targeted therapy, including to first-line osimertinib (75); concurrent disappearance of EGFR T790M mutation in conjunction to squamous transformation has been reported in tumors resistant to second- or third-line EGFR-targeted therapy (76). Aside from $E G F R$-mutant tumors, histologic transformation of $A L K$-rearranged lung adenocarcinoma into small cell carcinoma $(77,78)$ or squamous cell carcinoma (79) has been documented as a mechanism of acquired resistance to ALK-targeted therapy. In fact, histologic transformation is not unique to tumors treated by tyrosine kinase-targeted therapy and has been reported in KRAS-mutant lung adenocarcinomas resistant to immunotherapy (80). As targeted therapies evolve and become more widely adopted, transdifferentiation poses conceptual challenges on the molecular categories.

Fourth, can one tumor simultaneously belong to multiple molecular categories? While most driver mutations in lung adenocarcinoma (EGFR, KRAS, ALK, ROS1, and others) are generally considered to be mutually exclusive $(81,82)$, rare tumors with concomitant driver mutations have been reported (83-85). These conceptual challenges outlined above would need to be addressed in the implementation of molecular classification in lung cancer.

\section{Technical challenges of using molecular classification in lung cancer}

Considering the technical challenges of molecular classification, one should be cognizant of the limitations from the molecular diagnostic tools, implementation logistics, and the tumor tissue involved.

What evidence does one need to classify a tumor within a molecular category? Currently, the most commonly utilized tools include single-gene sequencing assay, targeted next-generation sequencing (NGS), and fluorescence in situ hybridization (FISH). Immunohistochemistry for ALK and ROS1 has been used in the identification and confirmation of $A L K$-rearranged and ROS1-rearranged lung tumors, respectively (22). Also, multiplex transcriptbased systems (such as NanoString) have been used for fusion detection in lung cancer $(86,87)$. Nevertheless, given different performance characteristics and technical limitations inherent in each assay, each tool will invariably be associated with false-positive and false-negative results. For instance, neither break-apart FISH, DNA-based hybrid capture with NGS, and RNA-based anchored multiplex
PCR with NGS (88) alone was entirely sensitive for detecting ROS1 rearrangement in lung adenocarcinoma in one study (89); while another study reported that $>20 \%$ of putative NTRK rearrangement in non-small cell lung carcinomas could not be confirmed by another molecular technique (21). Given that no single molecular detection tool is entirely sensitive and specific, a combination of tools using DNA-based NGS, RNA-based NGS, FISH, and/ or immunohistochemistry (if available) may be needed to ascertain the molecular characteristics, particularly in tumors with unusual clinicopathologic characteristics.

In addition to suboptimal sensitivity/specificity, there are issues in implementation logistics in using molecular classification. Molecular testing is often neither costeffective nor available in resource-limited settings. Since current reimbursement for molecular diagnostics is generally limited to patients with advanced disease, testing is rarely performed on early-staged tumors. One method to circumvent these limitations may be to use other surrogate tools to infer the molecular status. For instance, ALK immunohistochemistry has been optimized over the years and is currently considered to be equivalent to $A L K$ FISH and NGS testing in identifying $A L K$ rearrangements in lung cancer (22). Detection for most molecular alterations in lung cancer (such as EGFR, KRAS, ERBB2, RET, and MET) nonetheless relies primarily on molecular methods, with immunohistochemistry playing a minimal role currently (90).

Despite the importance of molecular status in therapy selection for many advanced lung cancer patients, the relevance of histologic analysis should again be emphasized. In addition to molecular testing, at least a portion of tumor tissue should always be preserved for histopathology; such practice can be challenging in cases with limited lesional tissue. Nonetheless, this allows one to ensure that there is sufficient lesional tissue for molecular testing, to exclude other etiologies for mass-forming lesions (such as infection), and to monitor for histologic transformation (such as small cell or squamous transformation) in patients treated by targeted therapy. Furthermore, lung is one of the most common sites for visceral metastases from diverse malignancies, and molecular testing results currently may not shed light on the tumor origin. While activating EGFR mutations are nearly exclusively found in non-small cell lung carcinomas, rearrangements of ALK, ROS1, RET, and NTRK have been reported in diverse tumor types (91). Mutations in KRAS or GNAS are present in a subset of carcinomas from diverse sites including lung, pancreas, and the gastrointestinal tracts, among others (92). Reliance 
on molecular information alone devoid of clinical and histologic contexts can thus be misleading.

\section{Conclusions}

Large-scale genomic studies in the last two decades have transformed our understanding on lung cancer genetics. Molecular diagnostics has been integrated in many laboratories and general medical practice, transforming how we diagnose and manage patients with lung cancer. While there are conceptual and technical hurdles to tackle in implementing molecular classification in the pathologic classification of lung cancer, such integrated histologicmolecular diagnosis may allow one to personalize and optimize therapy for patients with advanced lung cancer.

\section{Acknowledgments}

Funding: None.

\section{Footnote}

Provenance and Peer Review: This article was commissioned by the Guest Editor (Helmut H. Popper) for the series "New Developments in Lung Cancer Diagnosis and Pathological Patient Management Strategies" published in Translational Lung Cancer Research. The article was sent for external peer review organized by the Guest Editor and the editorial office.

Conflicts of Interest: Both authors have completed the ICMJE uniform disclosure form (available at available at http://dx.doi.org/10.21037/tlcr-20-153). The series "New Developments in Lung Cancer Diagnosis and Pathological Patient Management Strategies" was commissioned by the editorial office without any funding or sponsorship. The authors have no other conflicts of interest to declare.

Ethical Statement: The authors are accountable for all aspects of the work in ensuring that questions related to the accuracy or integrity of any part of the work are appropriately investigated and resolved.

Open Access Statement: This is an Open Access article distributed in accordance with the Creative Commons Attribution-NonCommercial-NoDerivs 4.0 International License (CC BY-NC-ND 4.0), which permits the noncommercial replication and distribution of the article with the strict proviso that no changes or edits are made and the original work is properly cited (including links to both the formal publication through the relevant DOI and the license). See: https://creativecommons.org/licenses/by-nc-nd/4.0/.

\section{References}

1. Travis WD, Brambilla E, Burke A, et al. Pathology and Genetics of Tumors of the Lung, Pleura, Thymus, and Heart. 4th ed. IARC Press: Lyon, France, 2015.

2. Swerdlow SH, Campo E, Pileri SA, et al. The 2016 revision of the World Health Organization classification of lymphoid neoplasms. Blood 2016;127:2375-90.

3. Louis DN, Perry A, Reifenberger G, et al. The 2016 World Health Organization Classification of Tumors of the Central Nervous System: a summary. Acta Neuropathol 2016;131:803-20.

4. Fletcher CDM, Bridge JA, Hogendoorn PCW, et al. WHO Classification of Tumours of Soft Tissue and Bone. 4th ed. Lyon: IARC Press, 2013.

5. Imielinski M, Berger AH, Hammerman PS, et al. Mapping the hallmarks of lung adenocarcinoma with massively parallel sequencing. Cell 2012;150:1107-20.

6. Cancer Genome Atlas Research Network. Comprehensive molecular profiling of lung adenocarcinoma. Nature 2014;511:543-50.

7. Yatabe Y, Kosaka T, Takahashi T, et al. EGFR mutation is specific for terminal respiratory unit type adenocarcinoma. Am J Surg Pathol 2005;29:633-9.

8. Yoshida Y, Shibata T, Kokubu A, et al. Mutations of the epidermal growth factor receptor gene in atypical adenomatous hyperplasia and bronchioloalveolar carcinoma of the lung. Lung Cancer 2005;50:1-8.

9. Rodig SJ, Mino-Kenudson M, Dacic S, et al. Unique clinicopathologic features characterize ALK-rearranged lung adenocarcinoma in the western population. Clin Cancer Res 2009;15:5216-23.

10. Inamura $\mathrm{K}$, Takeuchi $\mathrm{K}$, Togashi $\mathrm{Y}$, et al. EML4-ALK lung cancers are characterized by rare other mutations, a TTF1 cell lineage, an acinar histology, and young onset. Mod Pathol 2009;22:508-15.

11. Awad MM, Oxnard GR, Jackman DM, et al. MET Exon 14 Mutations in Non-Small-Cell Lung Cancer Are Associated With Advanced Age and Stage-Dependent MET Genomic Amplification and c-Met Overexpression. J Clin Oncol 2016;34:721-30.

12. Liu X, Jia Y, Stoopler MB, et al. Next-Generation Sequencing of Pulmonary Sarcomatoid Carcinoma Reveals 
High Frequency of Actionable MET Gene Mutations. J Clin Oncol 2016;34:794-802.

13. Tong JH, Yeung SF, Chan AW, et al. MET Amplification and Exon 14 Splice Site Mutation Define Unique Molecular Subgroups of Non-Small Cell Lung Carcinoma with Poor Prognosis. Clin Cancer Res 2016;22:3048-56.

14. Drilon A, Somwar R, Mangatt BP, et al. Response to ERBB3-Directed Targeted Therapy in NRG1-Rearranged Cancers. Cancer Discov 2018;8:686-95.

15. Fernandez-Cuesta L, Plenker D, Osada H, et al. CD74NRG1 fusions in lung adenocarcinoma. Cancer Discov 2014;4:415-22.

16. Go H, Kim DW, Kim D, et al. Clinicopathologic analysis of ROS1-rearranged non-small-cell lung cancer and proposal of a diagnostic algorithm. J Thorac Oncol 2013;8:1445-50.

17. Sholl LM, Sun H, Butaney M, et al. ROS1 immunohistochemistry for detection of ROS1-rearranged lung adenocarcinomas. Am J Surg Pathol 2013;37:1441-9.

18. Suehara Y, Arcila M, Wang L, et al. Identification of KIF5B-RET and GOPC-ROS1 fusions in lung adenocarcinomas through a comprehensive mRNAbased screen for tyrosine kinase fusions. Clin Cancer Res 2012;18:6599-608.

19. Lee SE, Lee B, Hong M, et al. Comprehensive analysis of RET and ROS1 rearrangement in lung adenocarcinoma. Mod Pathol 2015;28:468-79.

20. Wang R, Hu H, Pan Y, et al. RET fusions define a unique molecular and clinicopathologic subtype of non-small-cell lung cancer. J Clin Oncol 2012;30:4352-9.

21. Farago AF, Taylor MS, Doebele RC, et al. Clinicopathologic Features of Non-Small-Cell Lung Cancer Harboring an NTRK Gene Fusion. JCO Precis Oncol 2018;2018:PO.18.00037.

22. Lindeman NI, Cagle PT, Aisner DL, et al. Updated Molecular Testing Guideline for the Selection of Lung Cancer Patients for Treatment With Targeted Tyrosine Kinase Inhibitors: Guideline From the College of American Pathologists, the International Association for the Study of Lung Cancer, and the Association for Molecular Pathology. Arch Pathol Lab Med 2018;142:321-46.

23. Rekhtman N, Montecalvo J, Chang JC, et al. SMARCA4Deficient Thoracic Sarcomatoid Tumors Represent Primarily Smoking-Related Undifferentiated Carcinomas Rather Than Primary Thoracic Sarcomas. J Thorac Oncol 2020;15:231-47.

24. Cancer Genome Atlas Research Network. Comprehensive genomic characterization of squamous cell lung cancers. Nature 2012;489:519-25.

25. Campbell JD, Alexandrov A, Kim J, et al. Distinct patterns of somatic genome alterations in lung adenocarcinomas and squamous cell carcinomas. Nat Genet 2016;48:607-16.

26. Ohtsuka K, Ohnishi H, Fujiwara M, et al. Abnormalities of epidermal growth factor receptor in lung squamous-cell carcinomas, adenosquamous carcinomas, and large-cell carcinomas: tyrosine kinase domain mutations are not rare in tumors with an adenocarcinoma component. Cancer 2007;109:741-50.

27. Kang SM, Kang HJ, Shin JH, et al. Identical epidermal growth factor receptor mutations in adenocarcinomatous and squamous cell carcinomatous components of adenosquamous carcinoma of the lung. Cancer 2007;109:581-7.

28. Shi $\mathrm{X}, \mathrm{Wu} \mathrm{H}, \mathrm{Lu} \mathrm{J}$, et al. Screening for major driver oncogene alterations in adenosquamous lung carcinoma using PCR coupled with next-generation and Sanger sequencing methods. Sci Rep 2016;6:22297.

29. Peifer M, Fernandez-Cuesta L, Sos ML, et al. Integrative genome analyses identify key somatic driver mutations of small-cell lung cancer. Nat Genet 2012;44:1104-10.

30. Rudin CM, Durinck S, Stawiski EW, et al. Comprehensive genomic analysis identifies SOX2 as a frequently amplified gene in small-cell lung cancer. Nat Genet 2012;44:1111-6.

31. George J, Lim JS, Jang SJ, et al. Comprehensive genomic profiles of small cell lung cancer. Nature 2015;524:47-53.

32. Rekhtman N, Pietanza MC, Hellmann MD, et al. Next-generation sequencing of pulmonary large cell neuroendocrine carcinoma reveals small cell carcinomalike and non-small cell carcinoma-like subsets. Clin Cancer Res 2016;22:3618-29.

33. George J, Walter V, Peifer M, et al. Integrative genomic profiling of large-cell neuroendocrine carcinomas reveals distinct subtypes of high-grade neuroendocrine lung tumors. Nat Commun 2018;9:1048.

34. Marchetti A, Felicioni L, Pelosi G, et al. Frequent mutations in the neurotrophic tyrosine receptor kinase gene family in large cell neuroendocrine carcinoma of the lung. Hum Mutat 2008;29:609-16.

35. Fernandez-Cuesta L, Peifer M, Lu X, et al. Frequent mutations in chromatin-remodelling genes in pulmonary carcinoids. Nat Commun 2014;5:3518.

36. Simbolo M, Mafficini A, Sikora KO, et al. Lung neuroendocrine tumours: deep sequencing of the four World Health Organization histotypes reveals chromatinremodelling genes as major players and a prognostic 
role for TERT, RB1, MEN1 and KMT2D. J Pathol 2017;241:488-500.

37. Alcala N, Leblay N, Gabriel AAG, et al. Integrative and comparative genomic analyses identify clinically relevant pulmonary carcinoid groups and unveil the supracarcinoids. Nat Commun 2019;10:3407.

38. Marchevsky AM, LeStang N, Hiroshima K, et al. The differential diagnosis between pleural sarcomatoid mesothelioma and spindle cell/pleomorphic (sarcomatoid) carcinomas of the lung: evidence-based guidelines from the International Mesothelioma Panel and the MESOPATH National Reference Center. Hum Pathol 2017;67:160-8.

39. Alexandrov LB, Nik-Zainal S, Wedge DC, et al. Signatures of mutational processes in human cancer. Nature 2013;500:415-21.

40. Alexandrov LB, Kim J, Haradhvala NJ, et al. The repertoire of mutational signatures in human cancer. Nature 2020;578:94-101.

41. Zhang Z, Wang T, Zhang J, et al. Prognostic value of epidermal growth factor receptor mutations in resected non-small cell lung cancer: a systematic review with metaanalysis. PLoS One 2014;9:e106053.

42. Zhang SM, Zhu QG, Ding XX, et al. Prognostic value of EGFR and KRAS in resected non-small cell lung cancer: a systematic review and meta-analysis. Cancer Manag Res 2018;10:3393-404.

43. Kim H, Lee HJ, Hong H, et al. The prognostic implications of EGFR mutation and ALK rearrangement for the long-term outcomes of patients with resected lung adenocarcinomas. Thorac Cancer 2019;10:1619-27.

44. Wang Z, Yang H, Luo S, et al. Anaplastic lymphoma kinase gene rearrangement predicts better prognosis in NSCLC patients: A meta-analysis. Lung Cancer 2017;112:1-9.

45. Pao W, Miller V, Zakowski M, et al. EGF receptor gene mutations are common in lung cancers from "never smokers" and are associated with sensitivity of tumors to gefitinib and erlotinib. Proc Natl Acad Sci U S A 2004;101:13306-11.

46. Scarpino S, Rampioni Vinciguerra GL, Di Napoli A, et al. High prevalence of ALK+/ROS1+ cases in pulmonary adenocarcinoma of adoloscents and young adults. Lung Cancer 2016;97:95-8.

47. Shigematsu H, Lin L, Takahashi T, et al. Clinical and biological features associated with epidermal growth factor receptor gene mutations in lung cancers. J Natl Cancer Inst 2005;97:339-46.

48. Tanaka K, Hida T, Oya Y, et al. Unique prevalence of oncogenic genetic alterations in young patients with lung adenocarcinoma. Cancer 2017;123:1731-40.

49. Yoshida A, Tsuta K, Nakamura H, et al. Comprehensive histologic analysis of ALK-rearranged lung carcinomas. Am J Surg Pathol 2011;35:1226-34.

50. Jackman DM, Yeap BY, Sequist LV, et al. Exon 19 deletion mutations of epidermal growth factor receptor are associated with prolonged survival in non-small cell lung cancer patients treated with gefitinib or erlotinib. Clin Cancer Res 2006;12:3908-14.

51. Riely GJ, Pao W, Pham D, et al. Clinical course of patients with non-small cell lung cancer and epidermal growth factor receptor exon 19 and exon 21 mutations treated with gefitinib or erlotinib. Clin Cancer Res 2006;12:839-44.

52. Lin JJ, Cardarella S, Lydon CA, et al. Five-Year Survival in EGFR-Mutant Metastatic Lung Adenocarcinoma Treated with EGFR-TKIs. J Thorac Oncol 2016;11:556-65.

53. Singal G, Miller PG, Agarwala V, et al. Association of Patient Characteristics and Tumor Genomics With Clinical Outcomes Among Patients With Non-Small Cell Lung Cancer Using a Clinicogenomic Database. JAMA 2019;321:1391-9.

54. Sperduto PW, Yang TJ, Beal K, et al. Estimating Survival in Patients With Lung Cancer and Brain Metastases: An Update of the Graded Prognostic Assessment for Lung Cancer Using Molecular Markers (Lung-molGPA). JAMA Oncol 2017;3:827-31.

55. Mok TS, Wu YL, Thongprasert S, et al. Gefitinib or carboplatin-paclitaxel in pulmonary adenocarcinoma. N Engl J Med 2009;361:947-57.

56. Mok TS, Wu YL, Ahn MJ, et al. Osimertinib or PlatinumPemetrexed in EGFR T790M-Positive Lung Cancer. N Engl J Med 2017;376:629-40.

57. Kwak EL, Bang YJ, Camidge DR, et al. Anaplastic lymphoma kinase inhibition in non-small-cell lung cancer. N Engl J Med 2010;363:1693-703.

58. Solomon BJ, Mok T, Kim DW, et al. First-line crizotinib versus chemotherapy in ALK-positive lung cancer. N Engl J Med 2014;371:2167-77.

59. Shaw AT, Kim DW, Mehra R, et al. Ceritinib in ALKrearranged non-small-cell lung cancer. N Engl J Med 2014;370:1189-97.

60. Peters S, Camidge DR, Shaw AT, et al. Alectinib versus Crizotinib in Untreated ALK-Positive Non-Small-Cell Lung Cancer. N Engl J Med 2017;377:829-38.

61. Planchard D, Besse B, Groen HJM, et al. Dabrafenib plus trametinib in patients with previously treated BRAF(V600E)-mutant metastatic non-small cell lung 
cancer: an open-label, multicentre phase 2 trial. Lancet Oncol 2016;17:984-93.

62. Planchard D, Kim TM, Mazieres J, et al. Dabrafenib in patients with BRAF(V600E)-positive advanced non-smallcell lung cancer: a single-arm, multicentre, open-label, phase 2 trial. Lancet Oncol 2016;17:642-50.

63. Drilon A, Laetsch TW, Kummar S, et al. Efficacy of Larotrectinib in TRK Fusion-Positive Cancers in Adults and Children. N Engl J Med 2018;378:731-9.

64. Rudin CM, Poirier JT, Byers LA, et al. Molecular subtypes of small cell lung cancer: a synthesis of human and mouse model data. Nat Rev Cancer 2019;19:289-97.

65. Poirier JT, George J, Owonikoko TK, et al. New Approaches to SCLC Therapy: From the Laboratory to the Clinic. J Thorac Oncol 2020;15:520-40.

66. Lin JJ, Zhu VW, Yoda S, et al. Impact of EML4ALK Variant on Resistance Mechanisms and Clinical Outcomes in ALK-Positive Lung Cancer. J Clin Oncol 2018;36:1199-206.

67. Yasuda H, Kobayashi S, Costa DB. EGFR exon 20 insertion mutations in non-small-cell lung cancer: preclinical data and clinical implications. Lancet Oncol 2012;13:e23-31.

68. Wu JY, Yu CJ, Chang YC, et al. Effectiveness of tyrosine kinase inhibitors on "uncommon" epidermal growth factor receptor mutations of unknown clinical significance in non-small cell lung cancer. Clin Cancer Res 2011;17:3812-21.

69. Kobayashi S, Canepa HM, Bailey AS, et al. Compound EGFR mutations and response to EGFR tyrosine kinase inhibitors. J Thorac Oncol 2013;8:45-51.

70. Berger AH, Brooks AN, Wu X, et al. High-throughput Phenotyping of Lung Cancer Somatic Mutations. Cancer Cell 2016;30:214-28.

71. Kobayashi Y, Mitsudomi T. Not all epidermal growth factor receptor mutations in lung cancer are created equal: Perspectives for individualized treatment strategy. Cancer Sci 2016;107:1179-86.

72. Lee JK, Lee J, Kim S, et al. Clonal History and Genetic Predictors of Transformation Into Small-Cell Carcinomas From Lung Adenocarcinomas. J Clin Oncol 2017;35:3065-74.

73. Marcoux N, Gettinger SN, O'Kane G, et al. EGFRMutant Adenocarcinomas That Transform to Small-Cell Lung Cancer and Other Neuroendocrine Carcinomas: Clinical Outcomes. J Clin Oncol 2019;37:278-85.

74. Offin M, Chan JM, Tenet M, et al. Concurrent RB1 and TP53 Alterations Define a Subset of EGFR-Mutant Lung
Cancers at risk for Histologic Transformation and Inferior Clinical Outcomes. J Thorac Oncol 2019;14:1784-93.

75. Schoenfeld AJ, Chan JM, Kubota D, et al. Tumor Analyses Reveal Squamous Transformation and Off-Target Alterations As Early Resistance Mechanisms to First-line Osimertinib in EGFR-Mutant Lung Cancer. Clin Cancer Res 2020;26:2654-63.

76. Park S, Shim JH, Lee B, et al. Paired genomic analysis of squamous cell carcinoma transformed from EGFR-mutated lung adenocarcinoma. Lung Cancer 2019;134:7-15.

77. Caumont C, Veillon R, Gros A, et al. Neuroendocrine phenotype as an acquired resistance mechanism in ALK-rearranged lung adenocarcinoma. Lung Cancer 2016;92:15-8.

78. Levacq D, D'Haene N, de Wind R, Remmelink M, Berghmans T. Histological transformation of ALK rearranged adenocarcinoma into small cell lung cancer: A new mechanism of resistance to ALK inhibitors. Lung Cancer 2016;102:38-41.

79. Park S, Han J, Sun JM. Histologic transformation of ALKrearranged adenocarcinoma to squamous cell carcinoma after treatment with ALK inhibitor. Lung Cancer 2019;127:66-8.

80. Iams WT, Beckermann KE, Almodovar K, et al. Small Cell Lung Cancer Transformation as a Mechanism of Resistance to PD-1 Therapy in KRAS-Mutant Lung Adenocarcinoma: A Report of Two Cases. J Thorac Oncol 2019;14:e45-8.

81. Gainor JF, Varghese AM, Ou SH, et al. ALK rearrangements are mutually exclusive with mutations in EGFR or KRAS: an analysis of 1,683 patients with nonsmall cell lung cancer. Clin Cancer Res 2013;19:4273-81.

82. Lin JJ, Ritterhouse LL, Ali SM, et al. ROS1 Fusions Rarely Overlap with Other Oncogenic Drivers in NonSmall Cell Lung Cancer. J Thorac Oncol 2017;12:872-7.

83. Lo Russo G, Imbimbo M, Corrao G, et al. Concomitant EML4-ALK rearrangement and EGFR mutation in nonsmall cell lung cancer patients: a literature review of 100 cases. Oncotarget 2017;8:59889-900.

84. Tang Z, Zhang J, Lu X, et al. Coexistent genetic alterations involving ALK, RET, ROS1 or MET in 15 cases of lung adenocarcinoma. Mod Pathol 2018;31:307-12.

85. Schmid S, Gautschi O, Rothschild S, et al. Clinical Outcome of ALK-Positive Non-Small Cell Lung Cancer (NSCLC) Patients with De Novo EGFR or KRAS CoMutations Receiving Tyrosine Kinase Inhibitors (TKIs). J Thorac Oncol 2017;12:681-8.

86. Lira ME, Choi YL, Lim SM, et al. A single-tube 
multiplexed assay for detecting ALK, ROS1, and RET fusions in lung cancer. J Mol Diagn 2014;16:229-43.

87. Alì G, Bruno R, Savino M, et al. Analysis of Fusion Genes by NanoString System: A Role in Lung Cytology? Arch Pathol Lab Med 2018;142:480-9.

88. Zheng Z, Liebers M, Zhelyazkova B, et al. Anchored multiplex PCR for targeted next-generation sequencing. Nat Med 2014;20:1479-84.

89. Davies KD, Le AT, Sheren J, et al. Comparison of Molecular Testing Modalities for Detection of ROS1 Rearrangements in a Cohort of Positive Patient Samples. J
Thorac Oncol 2018;13:1474-82.

90. Hung YP, Sholl LM. Diagnostic and Predictive Immunohistochemistry for Non-Small Cell Lung Carcinomas. Adv Anat Pathol 2018;25:374-86.

91. Stransky N, Cerami E, Schalm S, Kim JL, Lengauer C. The landscape of kinase fusions in cancer. Nat Commun 2014;5:4846.

92. Ritterhouse LL, Vivero M, Mino-Kenudson M, et al. GNAS mutations in primary mucinous and non-mucinous lung adenocarcinomas. Mod Pathol 2017;30:1720-7.

Cite this article as: Hung YP, Chirieac LR. How should molecular findings be integrated in the classification for lung cancer? Transl Lung Cancer Res 2020;9(5):2245-2254. doi: $10.21037 /$ tlcr-20-153 